\title{
Tip Lesion Glomerulopathy
}

National Cancer Institute

\section{Source}

National Cancer Institute. Tip Lesion Glomerulopathy. NCI Thesaurus. Code C123123.

Segmental glomerulopathy of localized intracapillary foam cells with adjacent, often vacuolated glomerular epithelial cells confluent to the orig in of the proximal tubule. 